\title{
En Argentina, durante 2018 el aborto salió del armario pero no de la clandestinidad
}

In Argentina, during 2018 abortion came out of the closet but not from hiding

\begin{abstract}
Resumen
La autora de este artículo hace una síntesis de la evolución histórica y de las diferentes posturas religiosas frente al aborto, describe su epidemiología mundial y la posición de la Organización Mundial de la Salud frente a esta problemática, resume el desarrollo y el desenlace del recientemente instalado debate sobre la legalización del aborto en Argentina y, finalmente reflexiona sobre lo que nos ha dejado este proceso político.
\end{abstract}

\section{Abstract}

The author of this article summarizes the historical evolution and the different religious positions regarding abortion, describes its global epidemiology and the position of the World Health Organization in relation to this problem, summarizes the development and the outcome of the recently installed debate on the legalization of abortion in Argentina and, finally, reflect on what this political process has left us.

Discacciati V. En Argentina, durante 2018 el aborto salió del armario pero no de la clandestinidad. Evid Act Pract Ambul. 2018. 21(2) 42-44.

\section{Evolución histórica de las posturas frente al aborto}

El aborto es una práctica muy antigua, que en sus inicios no era cuestionada, sino todo lo contrario. Por ejemplo, en los pueblos primitivos el jefe de la familia tomaba decisiones sobre su descendencia desde antes del nacimiento, y lo hacía sin considerar la opinión de la mujer. En la Grecia Antigua fue un método de control familiar, ya que se entendía que el feto era parte de la madre y que era ella quien debía disponer sobre su cuerpo. El aborto se practicó tanto en la civilización griega como en la romana, insertando sustancias por el cuello del útero (procedimientos descriptos por Hipócrates) ${ }^{1}$.

El cuestionamiento del aborto empezó en Roma cuando las concepciones cristianas instalaron criterios de valoración de la vida y calificaron de homicidio al aborto provocado, implementando medidas contra la mujer como la pena de muerte, castigos corporales y el exilio ${ }^{2}$. Las creencias y las normas fueron modificándose. El Concilio de Vienne ${ }^{1}$ en 1312 y la Constitución Criminalis Carolina en 1533 fijaron y precisaron el inicio de la vida de los fetos masculinos y femeninos de manera arbitraria ${ }^{3,4}$. En 1588, el Papa Sixto $V$ proclamó que todos los abortos eran crímenes y debían ser castigados con la excomunión, manteniendo en adelante la iglesia la misma posición.

A fines del siglo XVIII y principios del XIX, los intelectuales empezaron a proponer que el aborto no fuese punible, favoreciendo la autonomía de la mujer por sobre la del feto. En 1882 , el Código español introdujo el aborto honoris causa con características mitigantes. Entrado ya el siglo XX, el Anteproyecto Federal Suizo de 1916 señaló en su artículo 112 que "...el aborto practicado por un médico titulado con el consentimiento de la embarazada, no es punible...". Esto marcó la tendencia abolicionista del siglo XX sobre el aborto.

La Unión Soviética fue el primer país que otorgó el derecho de "abortar a petición" en 1920. Continuaron con la despenalización los países nórdicos europeos: Islandia en 1935, Suecia en 1937 y Dinamarca en 1938. Para los años sesenta la mayoría de los países industrializados admitieron causales para el aborto legal. China e India lo liberalizaron, Gran Bretaña lo despenalizó en 1967, Francia en 1975 e Italia en 1978.

En los años 80 fue discutido en Estados Unidos y en las últimos tres décadas, la tendencia ha propiciado la despenalización el aborto, gracias a la presión del movimiento feminista. Si bien el marco legal es variable, en 49 países no hay restricciones para la realización el aborto y en 91 países está permitido sólo por causales $^{5}$.

Diferentes posturas religiosas respecto del aborto Argentina está atravesada por una diversidad cultural y religiosa y si bien nuestro estado no es confesional (es discutible si realmente es un estado laico), considero oportuno resumir las principales posturas religiosas respecto del aborto ya que han teñido el reciente debate.

Los budistas creen que la decisión es únicamente de la mujer. Los musulmanes consideran que el aborto es haram (pecado) y que solo puede ser admitido por motivos médicos que incluyen las malformaciones en el feto. Los evangélicos están divididos, admitiéndolo algunos en casos de abuso sexual o riesgo de la vida de la madre. Los judíos se oponen al aborto pero el feto no tiene igual status de vida que la madre y lo aceptan si hay riesgo para la madre. La iglesia armenia es contraria al aborto, aunque considera que no se puede decir que un embrión sea una persona y lo admite cuando el feto presenta complicaciones. Los testigos de Jehová, los mormones y los católicos se oponen al aborto $\sin$ excepciones ${ }^{6,7}$

\section{Reflexiones desde una mirada sanitaria}

¿Por qué nos importa la despenalización del aborto? ${ }^{8}$. En la bibliografía podemos encontrar muchas publicaciones respecto de la influencia del aborto inseguro sobre la mortalidad materna ${ }^{9}$. Además, disponemos de estimaciones nacionales ${ }^{\S}$ y de datos sobre el impacto que ha tenido en algunos países la legalización del aborto en la reducción de la mortalidad materna. En febrero de 2018, la Organización Mundial de la Salud (OMS) publicó las cifras del aborto, detallando que entre 2010 y 2014 hubo en el mundo un promedio anual de 56 millones de abortos provocados, con una tasa de incidencia anual de 35 abortos provocados por cada 1000 mujeres de 15 a 44 años de edad. La tasa de abortos fue mayor en las regiones en desarrollo que en las desarrolladas, lo que habla de unos 25 millones de abortos inseguros practicados anualmente en el mundo ${ }^{1}$.

En África y América Latina, tres de cada cuatro abortos practicados fueron inseguros. Es en este contexto que la OMS advierte que es posible prevenir casi todos los casos de muerte o discapacidad por un aborto mediante la educación sexual, el uso de métodos anticonceptivos eficaces, la práctica de abortos provocados en un contexto legal y seguro, y la atención a tiempo de sus complicaciones. La OMS remarca que el aborto es inseguro y peligroso cuando la legislación es restrictiva, cuando hay poca disponibilidad de servicios, cuando sus costos son elevados, cuando está presente la estigmatización de quien decide realizarlo, la objeción de conciencia del personal sanitario, y cuando se piden requisitos innecesarios como el asesoramiento obligatorio, información engañosa, autorización de terceros y/o pruebas médicas innecesarias. 
Son complicaciones del aborto inseguro el aborto incompleto, las hemorragias, la infección, la perforación uterina, los daños de genitales y de órganos internos y la muerte. Se calcula que, en las regiones desarrolladas, por cada 100.000 abortos peligrosos se producen 30 defunciones, aumentando ese número a 220 defunciones por cada 100.000 abortos peligrosos en las regiones en desarrollo. Los datos locales son claros en el reporte del Ministerio de Salud de la Nación de Argentina y se pueden consultar en el documento que acompañó la ponencia en el Congreso del Ministro de Salud ${ }^{10}$.

Estas cifras nos muestran que quienes estamos en riesgo somos las mujeres con un embarazo no deseado, especialmente si nos exponemos a un aborto clandestino. Ese riesgo puede reducirse con educación sexual, con métodos anticonceptivos eficaces y con la prestación de servicios legales de aborto seguro. Si repasamos el slogan de la campaña por el aborto legal: "Educación sexual para decidir, anticonceptivos para no abortar y aborto legal para no morir", podemos decir que es un excelente resumen de los documentos y las propuestas sanitarias internacionales.

El punto es que ante un embarazo no deseado y/o una maternidad no deseada, -cuestión que atañe a la mujer, puesto que es quien gesta y pone el cuerpo-, ¿por qué seguimos preguntando quién decide y con qué herramientas? Si se trata de una cuestión íntima de la mujer, por qué y cómo finalmente quedan involucrados en su decisión el estado, la iglesia, el sistema sanitario y la moral del vecino.

Podríamos decir que si el marco jurídico no acompaña las decisiones de la mujer, éstas se convierten en un delito. Por otro lado, también estamos en un problema si la ley acompaña a la mujer pero el sistema objeta este acompañamiento, ya que de ser así, se perpetúa la estigmatización social de la mujer y se propicia la clandestinidad. ¿Quién tiene el poder de decisión? ¿Importan aquí las cuestiones éticas y/o metafísicas, las creencias, las religiones, los prejuicios y la moral, cuando se están muriendo mujeres porque tomaron una decisión que de todos modos iban a concretar? Esto lleva a directamente a enfocar la cuestión política y a cabildear por la ampliación de los derechos de las mujeres.

\section{El debate que se instaló en Argentina}

En 2018 se abrió el debate en el Congreso Nacional de Argentina por decisión del Poder Ejecutivo Nacional. El debate ocupó las calles, los colegios, los medios de comunicación, los espacios laborales, la mesa familiar, las organizaciones civiles y fundamentalmente las organizaciones de mujeres y las organizaciones religiosas, que tuvieron un lugar destacado como grupos de presión. Todxs tuvimos y continuamos teniendo un lugar legitimado, ya sea por nuestra historia personal o la que nos fue compartida, por nuestras creencias o por el área disciplinar a la que pertenecemos. Hasta Ixs líderes de opinión se hicieron presentes y también se generaron construcciones falaces sobre las cifras, el impacto y los costos, y cada quien interpretó los mismos datos de manera diferente.

Pudimos seguir el debate de ambas cámaras del Congreso de la Nación y si no lo hicimos en forma sincrónica, lo hicimos de manera diacrónica. Como dije, este debate despertó cierto entusiasmo, y nos impulsó a ocupar la calle y a manifestar públicamente nuestra ideología. Así nos expusimos, ya que aprendimos que el silencio no suma en estas cuestiones. Las redes sociales se pintaron de colores, la ampliación de derechos se vistió de verde y la defensa de la vida por nacer lo hizo de celeste. Ambos colores se instalaron en el espacio público, cada unx desde su posición lo vivió con diferente intensidad, cada unx de nosotrxs desde nuestro color preferido. Nos encontramos con miradas cómplices entre desconocidxs que llevamos el mismo color, lo que nos acercó en los pensamientos.

Cabe resaltar el esfuerzo histórico de la militancia de los grupos en defensa de la autonomía de la mujer. Me refiero a las agrupaciones feministas y los colectivos que se han posicionado con solidez, como por ejemplo el \#NiUnaMenos, así como también sectores políticos que tenían la despenalización del aborto en su agenda. Lo remarco porque la prohibición del aborto es el estatus vigente $y$, justamente, la dificultad mayor la encuentran quienes persiguen un cambio. Ya sabemos de la resistencia al cambio, más difícil aun cuando hay sectores de poder que sostienen esa resistencia y cuando existen múltiples posibles intereses. Pero a pesar de ello, se llegó a un dictamen de la cámara baja y muchxs festejamos. Claro que hubo un despliegue de ponencias, Ixs intelectuales de diferentes sectores y áreas disciplinares se mostraron con argumentos robustos, cifras y fundamentaciones variadas, y los grupos opositores al cambio giraron prácticamente sobre un mismo eje argumental. Pero la alegría fue de corta duración, porque el senado rechazó el dictamen de la cámara de diputadxs. El senado representa los intereses de las provincias, Ixs diputadxs representan directamente al pueblo. El pueblo fue y es verde

No repararé en aspectos anecdóticos del debate en las cámaras, pues han sido objeto de cuestionamiento en cuanto a su veracidad y sus fundamentos. Esto ha motivado el intercambio de opiniones en las redes sociales, de publicaciones humorísticas y de caricaturas. A nivel mundial los medios siguieron el debate que se daba en nuestro país y salvo la Iglesia y los sectores vinculados a ésta, expresaron su decepción por el desenlace del proceso legislativo.

\section{Reflexiones finales}

Ahora bien, muchxs nos preguntamos cómo seguiremos. Las mujeres que quieren interrumpir su embarazo lo hacen y lo seguirán haciendo, por lo que seguirá habiendo abortos clandestinos. No importan sus motivos, importa que no accedan a una práctica segura y pongan en riesgo su vida. En párrafos previos expresamos que las cifras de la OMS nos dicen que son mujeres de 15 a 44 años. Muchas de ellas probablemente lleven adelante su hogar, con o sin hijos, todas con algún proyecto que ese embarazo no deseado o esa maternidad no deseada obstaculiza, algunas podrán entrar en contacto con organizaciones o profesionales que las cuidarán sin lucrar con ello, algunas con mejores medios económicos abortarán en consultorios privados y otras tantas usarán métodos inapropiados y peligrosos. Pero todas lo harán, no continuarán un embarazo para dar en adopción a ese niño, porque no se trata gestar para otro, un hijo no es "un objeto" que se "da" a otro como alternativa, porque omitiríamos una discusión, la de la maternidad. Todas abortarán en secreto, clandestinamente y a su manera. Tomo la frase con la que respondió el biólogo molecular Alberto Kornblihtt en el Congreso, pero en el contexto que estoy escribiendo y pienso "No está bien, está mal". No está bien es que el aborto sea clandestino y peligroso, no está bien la hipocresía, no está bien la manipulación, y está mal que una mujer muera por un aborto inseguro cuando disponemos de medios para que sea seguro.

Entonces, ¿qué podemos hacer? Primero tratar de recuperar lo positivo que se generó, por ejemplo:

- Que el misoprostol sea fabricado localmente y lo haya aprobado la Administración Nacional de Medicamentos, Alimentos y Tecnología Médica (ANMAT) para uso ginecológico ${ }^{11}$.

- Que la palabra aborto, ya no sea una palabra prohibida y haya salido del armario. La propuesta \#yoaborte de twitter lo dejó claro.

- Que no es una cuestión de Ixs pibxs jóvenes. Recordemos que en tiempos de nuestras abuelas no había anticonceptivos efi- 
caces, que muchas de ellas abortaron más de una vez, y que muchos de esos embarazos habían sido fruto de relaciones no consentidas.

- Que el aborto no es una cuestión de mujeres ricas o pobres, ya que atraviesa a todas las clases sociales. La diferencia está en la exposición al peligro y no en la decisión a abortar.

- Que se instaló en forma definitiva la Educación Sexual Integral $\left(\mathrm{ESI}^{12}\right)$, ya que los grupos opositores que antes obstaculizaban su implementación se escudaron en ella como estrategia para la prevención del aborto. Esto implica admitir que existe una sexualidad del goce y no solo una sexualidad reproductiva. Por otro lado, vale recordar que los métodos anticonceptivos eficaces no incluyen a la abstinencia ni al método del ritmo.

- Que la interrupción por causales es ley desde 1921 y que es necesario garantizar a las mujeres su derecho a interrumpir el embarazo por estas razones y que ya no podemos admitir la ausencia de protocolos ${ }^{13}$.

Queda la satisfacción del ejercicio democrático, como lo fue también para la ley de divorcio y para el matrimonio igualitario, con la diferencia que esta vez dejó un sabor amargo por parte del senado. Sin embargo, cada unx de nosotrxs tendrá su lista y esa lista ayudará a decidir el próximo voto.
Y para finalizar, en lo personal creo fuertemente que no somos Ixs mismxs que antes de junio, julio y agosto de 2018. Este debate nos ha transformado, ya que nos atravesó cada testimonio y nos vimos identificadxs o representadxs en muchas de las ponencias. Nos reconocimos en la calle, en los gestos, en la plaza del Congreso durante las vigilias y en cada intervención pública de visibilización. Porque firmamos cartas abiertas y petitorios, porque enviamos correos electrónicos a senadores y diputados, denunciamos inconsistencias, porque Ixs estudiantes levantaron sus carteles y se pudieron expresar. Estoy convencida que estamos ejercitando y aprendiendo a ser más tolerantes. Porque el reclamo de la ley continua y cada vez va a ser más potente. Porque no toleramos que en esta primera semana de agosto 2018 ya hayamos contado a dos mujeres fallecidas por aborto inseguro, y hacemos responsable al senado por sus pérdidas. Y por sobre todas las cuestiones, como médica comprometida con la salud de las mujeres, quienes nos posicionamos en una postura del cuidado, sin juzgar las decisiones que cada una tome, mi/nuestro objetivo es acompañar, y ofrecer el mejor cuidado posible con los medios que disponemos. En "este hacer", sabemos que una marea social nos legitima y es de color verde.

Agradecimientos: Quiero agradecer a Ixs que pusieron su voz y su cuerpo en el debate, a todxs Ixs que acompañaron con el pañuelo verde, así como también a aquellxs cuyas creencias no aceptan la interrupción del embarazo, pero se mostraron respetuosos, tolerantes y no obstaculizaron el reclamo de un paraguas legal que cubra a todas las mujeres respetando todas las creencias y amplíe derechos para que no haya \#NiUnaMenos \#seraley

Por ellas, por las que no conocimos y para que no haya más mujeres en esta situación, hago un mini resumen de algunos casos resonantes: Por el caso de LMR (2011), a quien la provincia y la secretaria DDHH pidieron públicamente disculpas.

Por el caso de Belén (Tucumán, 2014), condenada en 2016 ya que sus derechos fueron vulnerados.

Por María Magdalena (Tucumán, 2012), a quien operaron sin anestesia.

Por la joven de 16 años a quien le negaron una interrupción legal del embarazo (ILE) por objeción de conciencia y la derivaron a otra jurisdicción.

Por Juana. Salteña y wichi de 12 años, violada y con un embarazo con anencefalia, a quien no le ofrecieron opciones.

Por la joven salteña de 14 años, abusada, a quien le impidieron interrumpir su embarazo por un amparo de la provincia.

Por Mónica (Entre Ríos, 2011). Ella, con tetralogía de Fallot, tuvo un ACV pero la derivaron al Hospital Posadas de Buenos Aires.

La joven que en Tierra del Fuego fue procesada por la denuncia de los médicos.

Por Mónica, de 13 años, a quien en la Provincia de Buenos Aires le negaron su derecho a realizar un ILE.

Por Mónica, de 13

https://amnistia.org.ar/wp-content/uploads/delightful-downloads/2017/05/01-Informe-estado-ILE.pdf - https://www.pagina12.com.ar/diario/sociedad/3-261711-2014-12-11.html

Recibido el 20/08/2018 y aceptado el 28/08/2018.

\section{Referencias}

1. Zirmmernman M. Aborto. Leyes prácticas: Legislación Política No. 3, abril, 1977

2. Aguirre Zozoya F. Epidemiología del aborto. Ginecol Obstet Mex 1976; 22(134):1675-90. https://revistas.ucm.es/index.php/ASEM/article/viewFile/ASEM6868110011A/18515

3. Cabrera Forneiro J. La Medicina Legal hoy. ¿Para qué? SEMERGEN. 2005;31 (3):101-2

4. Marquard, The first systematic criminal code of early european modernity: the constitutio criminalis Carolina of 1532 . Pensamiento Jurídico, No. 45 , ISSN 0122 - 1108 , Enerojulio, Bogotá 2017, PP. 15-60

5. Center for Reproductive Rights. Disponible en URL: http://worldabortionlaws.com (último acceso el 28/08/2018).

5. Center for Reproductive Rights. Disponible en URL: http://worldabortionlaws.com (último acceso el 28/08/2018).
6. Irrazábal M La religión en las decisiones sobre aborto no punible en la Argentina. Revista Estudos Feministas, 23(3), 735-759. 2015

7. Himitian E. Aborto: los budistas son los más permisivos y los católicos y Testigos de Jehova, los más estrictos. Diario La Nación $21 / 3 / 2018$ (Disponible en URL: https://www. lanacion.com.ar/2118936-que-opinan-las-distintas-religiones-sobre-el-aborto).

8. Organización Mundial de la Salud. Prevención del aborto peligroso http://www.who.int/es/news-room/fact-sheets/detail/preventing-unsafe-abortion

9. Romero M y col. La situación de la mortalidad materna en la Argentina. OSSyR Ciudad Autónoma de Buenos Aires Argentina - Número 1 Abril 2010. http://www.ossyr.org.ar/ pdf/hojas informativas/Hoja Informativa_OSSyR 01.pdf

10. Adolfo Rubinstein. Despenalización del Aborto en Argentina. Un abordaje desde la Salud Pública. Ministerio de Salud de la Nación 2018. Disponible en URL: https://www. youtube.com/watch?v=Zrxw6g7a8pg (último acceso 28/08/2018).

youtube.com/watch?v=Zrxw6g7a8pg (último acceso 28/08/2018).

11. Sistema nacional de farmacovigilancia. Misoprostol. Ministerio de salud de la nación Agosto $2018 \mathrm{http} / / /$ www.anmat.gov.ar/farmacovigilancia/Misoprostol.asp

12. Programa Nacional de Educación Sexual Integral de Argentina. Disponible en URL: https://www.argentina.gob.ar/educacion/esi (último acceso 28/08/2018).

13. Código Penal de la Nación Argentina. Artículo 86, inciso 2. Disponible en URL: http://servicios.infoleg.gob.ar/infoleglnternet/anexos/15000-19999/16546/texact.htm\#15 (último acceso 28/08/2018). 